\title{
LA VIDA DE LA SACRATÍSSIMA VERGE MARIA Y EL CARTOIXÀ DE JOAN ROÍS DE CORELLA: DATOS EXTERNOS*
}

\author{
Josep Lluís Martos \\ Universitat d'Alacant
}

La vida de la sacratíssima Verge Maria de Joan Roís de Corella presenta variantes importantes entre sus dos versiones conservadas, una manuscrita y otra impresa, ${ }^{1}$ que han dado lugar a desacertadas interpretaciones y consecuentes decisiones ecdóticas por parte de Miquel i Planas. ${ }^{2}$ Entendiendo que se trataba de dos versiones de autor, consideró definitivo el texto impreso, mientras que el manuscrito habría transmitido una redacción primitiva, 'un estat anterior, encara imperfet, de La Vida de la Verge Maria' (Miquel i Planas 1913: 392). Más allá de que la materialidad del impreso no es previa a la confección del Cançoner de Mayans, ${ }^{3}$ eso tampoco negaría la indudable anterioridad textual de la versión manuscrita, ni implicaría tampoco un argumento para atribuir a Corella, por inercia, la responsabilidad de todas las variantes y variaciones que presenta el texto impreso, muchas de las cuales se debieron de originar en el proceso editorial. Dado que los datos físicos y contextuales que enmarcan la edición de este poema son esenciales para entender el proceso, considero su estudio como objetivo último de este trabajo, sobre el cual se fundamentará posteriormente el análisis interno de las variantes.

El punto de partida es, sin duda, la existencia de dos datos concretos y documentados en cuanto a la relación directa de Joan Roís de Corella con la edición del Cartoixà. En primer lugar, la rúbrica inicial y el colofón de alguno de los volúmenes impresos de esta traducción nos advierten de que fue 'arromançat, corregit, smenat y ben examinat' por Corella. En segundo lugar, según nos informa su inventario de bienes, al morir quedaron en su celda del convento de San Francisco ${ }^{4}$ una serie de libros de teología

\footnotetext{
* Este trabajo se enmarca en el proyecto FILO/FFI2011-25266 del Ministerio de Economía y Competitividad.

${ }^{1}$ El Cançoner de Mayans (Martos 1999, 2001 y 2005) y las dos ediciones de Lo Primer del Cartoixà, al final de las cuales se incluyó este poema: el incunable del 13 de abril de 1496 y el impreso del 16 de octubre de 1518.

2 'Hem donat per primitiva la lliçó manuscrita y per definitiva la estampada en Lo Primer del Cartoxà, en primer lloc perquè aquesta estampació és evidentment posterior a la formació d'aquell volum manuscrit de les Obres de Mossèn Corella; y en segón lloc, perquè'l caràcter de les variants qui apareixen en el text imprès, revela prou clarament quin fou el propòsit de l'autor al modificar alguns dels versos de la Vida de la Verge: aquest propòsit no fou altre que l'evitar algunes ambigüitats de concepte, qui hauríen pogut fins ésser titllades d'irreverència, si algún comentarista repelós hagués fet propòsit d'impugnar els rims, per altra part rublerts de noble y alta inspiració, de Mossèn Corella' (Miquel i Planas 1913: LXXVI).

3 Porque el primero es de 1496 y el segundo, con un terminus post quem de 1482, se pudo haber recopilado hacia 1497 o poco después (Martos 2008: 105).

4 El más grande de los existentes en Valencia, que ocupaba la extensión total de la actual plaza del Ayuntamiento. Fue destruido en 1891.
} 
que Corella habría donado en vida a los frailes, entre los que se encontraban 780 ejemplares del Primer i del Quart del Cartoixa. ${ }^{5}$

La posesión de tal número de volúmenes de dos de los impresos del Cartoixà que llegó a ver publicados en vida, podría sugerir que Corella hubiese participado económicamente en la edición de éstos, aunque no se conoce ningún caso de un editor comercial que coexista con uno literario, ni Corella aparece como tal en el contrato firmado por Miquel Albert con el impresor Lope de la Roca (Serrano y Morales 1898-1899: 6). En ese caso, se trataría, sin duda, de algún acuerdo privado al que habría llegado Corella con este editor. Estos ejemplares del Quart a los que se refería el inventario de bienes de Corella debían de pertenecer a la edición impresa por Lope de la Roca el 26 de noviembre de 1495 y no a la editio princeps, ya que de sus talleres salieron también los volúmenes del Primer que se encontraban junto a éstos.

El impulsor de la editio princeps debió de ser Jaume de Vila, con quien los impresores Pedro Hagenbach y Leonardo Hutz habían trabajado en exclusividad (Serrano y Morales 1898-1899: 7), según concluye a partir de este dato Haebler (1903-1917, I: 179). Y no parece incorrecta la deducción, si tenemos en cuenta una serie de circunstancias que enmarcaron este proyecto editorial. En primer lugar, el Quart avanza su publicación a las tres partes previas, que debía de tener traducidas Corella por aquel entonces, lo que parece responder a criterios comerciales ${ }^{6}$ y estar relacionado, precisamente, con la edición de Lo Passi en cobles (1493), de estos mismos impresores y editor. En segundo lugar, Vila y Corella se conocían bien, al menos desde la impresión de su Psalteri, cuyo editor, Joan Rix de Cura, tenía a Vila como principal hombre de confianza, a quien encargó, de hecho, la administración de sus bienes tras su muerte (Serrano y Morales 1898-1899: 484-489); es lógico que, ante el funcionamiento editorial de esta obra de Corella — que conocía de primera mano, porque fue él quien gestionó la mayor parte de su venta-, Vila se planteara la edición de la última parte del Cartoixà, con los episodios de la Pasión, que tan buenos resultados comerciales le dieron en Lo Passi en cobles. Finalmente, la relación entre ambas

\footnotetext{
5 Fue Martí de Riquer (1964, III: 258) quien dió la primera noticia de este documento. No aportaba, sin embargo, el texto exacto del documento, que transcribo aquí: 'En la dita cambra restaren molts libres de Theologia y altres, y aquells lo dit defunct en sa vida donà als frares de sanct Francesch. Ítem set-cents huytanta volums que són lo quart y lo primer del Cartoixà. Emperò, com en la dita casa havia statger dalt, no fonch atrobat més en aquella com lo restant que en la casa era (fos) del dit statger'. Sabemos desde Almiñana (1984-1985, II: 412) que Isabel Martínez de Vera vendió estos ejemplares a Joan Caulet, APCCV, Protocols de Pere Andreu, núm. 13.874, 1 de març del 1500. Abel Soler (2014) transcribe el albarán y, a partir de él, documenta la venta el 23 de enero de 1498.

6 No deixarà de semblar estrany que’l llibre comencés a ésser estampat precisament pel seu darrer volum; emperò no ha de veure's en això sinó una conveniencia editorial: Lo Quart del Cartoxà correspòn a la Passió de Nostre Senyor, y sembla que havia d’interessar més al públic que les altres parts, que, com veurem, foren estampades en anys successius' (Miquel i Planas 1913: XX).
} 
obras y sus editores se evidencia con la aparición del poema corellano de la Oració como broche del impreso, cumpliendo, precisamente, la misma función que en el volumen de Fenollar y Martínez, en un tipo de intervencionismo atribuible al editor más que a los impresores. ${ }^{7}$

Haebler piensa que esta segunda edición llegó como respuesta a las prisas de la editio princeps, de manera que Corella sí que la habría revisado en esta ocasión: 'Esta edición, mucho más rara que la precedente, parece que es reimpresión de ella, pero revisada por el traductor Ruiz de Corella. Esto hace suponer, que la primera se hizo con premura y sin la diligencia necesaria' (1903-1917, I: 180). De esta afirmación se derivaría implícitamente, por lo tanto, que Corella no habría revisado su original en la editio princeps, como podría confirmar la ausencia de este dato tanto en su rúbrica inicial ${ }^{8}$ como en su colofón. ${ }^{9}$ En tal supuesto, cobraría especial sentido la advertencia de Antoni Ferrando en cuanto a que 'no hi havia cap respecte pel text de l'autor, fins i tot si era coetani' (1999: 113), ilustrándolo, precisamente, con el ejemplo de intervencionismo de Jaume de Vila en el título del incunable de Lo Passi en cobles, que no sería atribuible a Fenollar.

El afán comercial de Jaume de Vila debió de ser, sin duda, el origen del proyecto editorial, pero sorprende la irrupción en escena de Miquel Albert, con —al menos- el consentimiento de Joan Roís de Corella, como se deduce de la posesión de ejemplares de estos impresos en el momento de su muerte, un año después de la edición del Primer del Cartoixà. Algún desencuentro editorial debió de tener Corella con Vila para que, sólo tres meses después o, incluso, antes, negociara una nueva edición del Quart con Albert, que firmó el contrato de impresión ya el 30 de mayo de aquel año. Es probable que se hubiese agotado la editio princeps, porque el Cartoixà fue un verdadero éxito de ventas tanto en catalán como en castellano, ${ }^{10}$ pero no podemos descartar que esta nueva edición buscase competir con la patrocinada por Vila. En cualquier caso, si no un problema de entendimiento por otras condiciones editoriales, debió de ser una falta de interés de Vila por imprimir el resto de volúmenes del Cartoixà, siempre que la editio princeps del Quart hubiese sido de mutuo acuerdo y consentida por el autor. Por una razón u otra, el hecho

\footnotetext{
7 Miquel i Planas, de hecho, destaca este aspecto en relación con el inicio de la impresión del Cartoixà a partir del Quart: 'La Oració de Mossèn Corella, qui figura estampada a la fi d'aquest llibre, havia estat ja impresa abans, com hem vist, a la fi de La Istoria de la Passió, de Bernat Fenollar y Pere Martínez, que, com veurem, foren estampades en anys successius' (1913: XX).

8 'Comença lo Quart del Cartoxà, aromançat per lo reverent e magnífich mestre Joan Rö̈ç de Corella, cavaller e mestre en sacra theologia'.

9 'Ad laudem et honorem Domini nostri Jesu Christi eiusquem virginis Mariae matris sue fuit impressum in civitate urbis Valentie die XVI februarii anno Domini MCCCCLXXXXV'.

${ }^{10}$ De hecho, un éxito comercial así era posible, como demuestra que, según me informa Maria Mercè López Casas, Estanislao Polono imprime en Sevilla dos ediciones de los Claros varones de España de Hernando del Pulgar con menos de un mes de diferencia: el 24 de abril y el 22 de mayo de 1500.
} 
evidente es que Joan Roís de Corella ofreció la edición de su obra a Miquel Albert —el editor valenciano que mayor competencia debía de implicar para Vila por aquel entoncesy éste mandó imprimir su Quart del Cartoixà con cierta premura. La publicación del Primer también por Lope de la Roca y patrocinado por Miquel Albert, que suponía la entrega del original por parte de Corella, así como su posesión de ejemplares de ambas ediciones, evidencia que el poeta se involucró personalmente en este episodio editorial, más allá de si eso implicaba una cofinanciación, que no es determinante para los objetivos de este trabajo. El compromiso de completar la edición del Cartoixà debió de estar sobre la mesa —como se deriva de la pronta edición del Primer-, pero debió de quedar interrumpido por la muerte de Corella en 1497 y por la de Lope de la Roca al año siguiente. Si Joan Roís de Corella sólo disponía entonces de ejemplares del Primer y del Quart del Cartoixà, debió de ser porque fueron los únicos que se habían publicado antes de su fallecimiento: no fue hasta unos años después que se retomó, con la publicación del Segon (Valencia, 1500) y de la Terça part del Cartoixà (c. 1502).

Parece confirmar esta hipótesis el hecho de que la edición de la segunda parte advierta en su colofón ${ }^{11}$ que Corella llegó a revisarla antes de su muerte, lo que indicaría que debía de estar preparándose para las prensas y quedó interrumpida. Habiendo fallecido Lope de la Roca el 17 de noviembre de 1498 (Serrano y Morales 1898-1899: 9), debió de ser Cristóbal Cofman (Haebler 1903-1917, I: 178) quien se encargó de esta impresión, en un proyecto editorial que no podemos deslindar necesariamente de Miquel Albert, cuya muerte habría que datar el 17 de octubre de 1502 (Serrano y Morales 1898-1899: 9). La Terça part del Cartoixà se llevó a las prensas poco antes o poco después de morir Albert, pero no debió de ser en Valencia. ${ }^{12}$ Aunque Haebler considera en un principio que Corella 'tradujo también la tercera parte, pero no se imprimió sino en 1502' (1903-1917, I: 179), en las ampliaciones y correcciones a su catálogo sigue las hipótesis infundadas de Ernst, que advierte que 'los tomos I, III y IV (Bibliogr. Iber. n 374, 376 y 377) serían impresos por el mismo impresor y con caracteres idénticos' (1903-1917, II: 108). A pesar de que le parece

\footnotetext{
11 'A honor, laor y glòria de la Trinitat sanctíssima acaba la segona part del Cartoxà, traduhida de la latina lengua en valenciana prosa per lo molt reverend e magnífich mestre en sacra theologia, mossén Johan Roïç de Corella, y per aquell diligentment ans de la mort sua corregida hi examinada, la qual fon aprés ab gran vigilància effigiada y empremtada en la ínclita metropolitana ciutat de València, en lo any jubileu de la nativitat jocundíssima de nostre Senyor Déu Jesucrist mil cinch-cents'. Y en la rúbrica inicial también hace alusión a la corrección por parte del autor, según el modelo de los impresos de Lope de la Roca: 'Comença lo Segon del Cartoxà, arromançat, corregit, smenat e ben examinat per lo reverend e magnífich mestre Johan Roïç de Corella, cavaller, mestre en sacra theologia'.

12 Así lo indican algunos rasgos lingüísticos, según me advierte Joan M. Furió. A esto hay que añadir la diferente calidad editorial, que contrasta con el resto de impresos del Cartoixà, especialmente los de Lope de la Roca, además de que no indica en la rúbrica inicial una posible revisión por parte de Corella: 'Comença la terça part del Cartoxà, trelladat de latí en romanç per lo reverent mestre Corella’. El impreso no tiene colofón.
} 
complicado distinguir entre los caracteres de Hagenbach y Hutz, por un lado, y de Lope de la Roca, por el otro, concluye que, si el Quart y el Primer fueron impresos por éste último y si Ernst decía que los tres impresos eran de un mismo taller, entonces la Terça part del Cartoixà es de Lope de la Roca y 'se debe presumir que pertenece a los mismos años' (19031917, II: 109), lo que se funda en una serie de silogismos bastante débiles. Este gazapo ha tenido fortuna editorial y así lo recogen Miquel i Planas (1913: XXII), Ribelles Comín (1915: 538) y Martí de Riquer (1964, III: 270), en cuanto a la fecha, y ha provocado que se atribuya esta edición a Pedro Hagenbach y Leonardo Hutz (García Craviotto 1989-1990) o a Lope de la Roca (Romero Lucas 2003: 300 y 2005), indistintamente. ${ }^{13}$ Por las diferentes características de los impresos y, sobre todo, porque Corella no disponía de ejemplares de la Terça part, que, por otro lado, no tendría sentido que se hubiese adelantado al Primer ni cumpliría los plazos de los cinco o seis meses que requeriría tal edición; por todo ello, acepto y mantengo la acertada hipótesis inicial de Haebler, que data este impreso hacia 1502.

De todo esto, se concluye que Corella no parece haber intervenido en la editio princeps del Quart del Cartoixà, lo que contrasta con su proximidad al proyecto editorial de Miquel Albert, que imprimió con Lope de la Roca la segunda edición del Quart y el Primer, además de, muy probablemente, el Segon con Cristóbal Cofman. Siguiendo el modelo de la rúbrica inicial y del colofón de esta edición del Quart, ${ }^{14}$ los tres impresos indican que Joan Roís de Corella revisó y enmendó el texto del Cartoixà que contenían. ${ }^{15}$ Y precisamente en

\footnotetext{
${ }^{13}$ Lourdes Soriano Robles et al. (2007) llevan esta fecha de $c .1495$ al título de su trabajo y remiten a la doble adscripción a diferentes impresores por parte de García Craviotto y Romero Lucas. Este artículo presenta la descripción y catalogación de todos los ejemplares conocidos de la Terça part hasta entonces, sin duda el impreso más desconocido del Cartoixà de Corella.

14 'Comença lo Quart del Cartoxà, aromançat, corregit, smenat e ben examinat per lo reverent e magnífich mestre Joan Roïç de Corella, cavaller e mestre en sacra theologia' y 'Ad laudem et honorem Domini nostri Jesu Christi eiusquem virginis Mariae matris impressum fuit opus istud, correctum nec non diligentissime emendatum per reverendissimum dominum Joannem Roiç de Corella, doctorem sacre theologie, die vigesimo sexta mensis novembris, anno Domini millesimo quadringentesimo nonagesimo quinto'. Esta información se mantiene en la edición del Quart del Cartoixà de 24 de mayo de 1513 (València, Jorge Costilla), lo que indica que debió de usar el texto impreso por Lope de la Roca como original de imprenta, cuyo colofón traduce del latín literalmente: 'Comença lo Quart del Cartoxà, aromançat, corregit, smenat e ben examinat per lo reverent e magnífich mestre Johan Roïç de Corella, cavaller e mestre en sacra theologia' (rúbrica inicial); 'A lahor e glòria de nostre Senyor Jesucrist e de la sacratíssima Verge Maria, mare sua, és acabat lo present libre, nomenat lo Quart del Cartoxà, corregit y smenat per lo molt reverent e magnífich mestre Joan Roïç de Corella, cavaller e mestre en sacra theologia. E fon empremptat en la molt insigne e metropolitana ciutat de València per Gorge Costilla a XXIII dies del mes de maig de l'any MDXIIJ' (colofón).

${ }^{15}$ En el Primer del Cartoixà: 'Comença lo Primer del Cartoxà, arromançat, corregit, smenat e ben examinat per lo reverend e magnífich mestre Joan Roïç de Corella, cavaller e mestre en sacra theologia' (rúbrica inicial); 'Acaba la primera part del Cartoxà en la vida de Jesús, Déu hi Senyor nostre, trelladada de latí en valenciana lengua per lo magnífich hi reverend e magnífich mestre Joan Roïç de Corella, cavaller hi mestre en sacra theologia, hi per ell mateix corregit, smenat hi ben examinat. A pregàries del molt reverend hi magnífich frare Jaume del Bosch, cavaller religiós del sagrat orde de la sacratíssima nostra Verge Maria de Montesa. Stampat en la insigne ciutat de València, a tretze de abril, any de la salut nostra MCCCCLXxxxvj' (colofón). Del Segon he transcrito ambos textos en una nota anterior.
} 
esto se basa Miquel y Planas para preferir la versión impresa de la Vida frente a la manuscrita. ${ }^{16}$ Se trata, por lo tanto, de un aspecto clave para los objetivos de este trabajo.

Podría hacernos dudar de la veracidad de esta información la frecuencia con la que estos datos del colofón falsean la realidad, como ocurre, por ejemplo, en la Bíblia valenciana de 1478, en la editio princeps de los Furs e ordinations del Regne de València, en el Liber elegantiarum de Joan Esteve o en el mismísimo Tirant lo Blanc (Ferrando 1999: 116-117). Sin duda, es una vía para difundir información con carácter comercial, que, con estos fines, se llega a manipular frecuentemente. En estos términos, atribuir a Corella la corrección minuciosa del Cartoixà en una edición que había de sustituir la princeps, salida de las prensas unos meses antes, no era una decisión arbitraria y casual por parte del editor, sino que tenía una función claramente propagandística: era habitual en la imprenta antigua añadir algún aliciente en las nuevas ediciones de una obra, para incentivar su compra, incluso por aquellos que ya la habían adquirido previamente.

Más allá de que Corella hubiese intervenido de facto en la corrección de las ediciones de Albert, es indudable que existió un corrector de imprenta profesional. Dudo mucho de que dependiesen de Joan Roís de Corella todas las correcciones lingüísticas aplicadas al texto para adaptarlo a las convenciones ortográficas, morfosintácticas y léxicas de la imprenta, alguna de las cuales llegó a propiciar errores métricos. Por el tipo de variantes existente entre ambas ediciones, parece evidente que se utilizó como original de imprenta la edición patrocinada por Vila y debió de ser sobre ella, a manera de galeradas, que Roís de Corella aplicó correcciones. ${ }^{17}$

A diferencia de lo que ocurre en la Vida, entre las versiones impresas y la manuscrita de la Oració no hay variantes sustanciales. ${ }^{18} \mathrm{Y}$ esto llama la atención, porque podría indicar que la corrección de la editio princeps del Quart no debió de ser tan profunda como se anunciaba o bien no haber alcanzado a la poesía de remate; la revisión sobre el impreso, en cualquier caso, lo limitaba en mayor medida que una nueva copia manuscrita, pasada a limpio, como debió de ocurrir con la Vida. No hay ningún criterio, por lo tanto, que justifique la autoridad del testimonio impreso de la Oració por encima del manuscrito, que tiene la virtud de no incorporar unos rasgos lingüísticos propios de la imprenta y, en principio, ajenos al autor.

\footnotetext{
16 'El text donat a continuació es el qui apareix com a definitiu en la edició de "Lo Primer del Cartoxà" (P), qui fou corregitda pel meteix Roiç de Corella’ (Miquel i Planas 1913: 392).

${ }^{17}$ Como, de hecho, es habitual en la imprenta: 'De fet, el treball de correcció i composició era tan costós que hom preferia fer les reedicions d'una obra a partir de la primera edició i no d'un text revisat adequadament. Resultava més fàcil, més còmode i més econòmic' (Ferrando 1999: 112).

18 En este sentido, aunque Miquel i Planas optó por editar la Oració a partir de la versión manuscrita y no de la impresa, cumpliendo en principio las mismas condiciones textuales que la Vida, no lo justifica.
} 
Ahora bien, la editio princeps del Primer del Cartoixà es una obra que llevó a imprenta por primera vez el editor Miquel Albert, con el consentimiento y la más que probable colaboración de Joan Roís de Corella. Al no depender de una edición previa, el proceso de corrección debió de ser más intenso, desde todas las perspectivas y en todos los estadios en que se podría revisar un texto en la imprenta, incluyendo la enmienda por motivos de prevención teológica. No tenemos la perspectiva de un impreso anterior para valorar el grado de intervencionismo, a diferencia de lo ocurrido con el Quart, ni conservamos ninguna copia manuscrita, pero sorprende que en esta ocasión el poema de remate sí que contenga variaciones importantes respecto de la versión del Cançoner de Mayans y que la mayor parte de éstas sean fácilmente relacionables con la imprenta.

Y eso a pesar de tratarse de un poema de remate (Martos en prensa), que se incluyó siguiendo el modelo de la Oració, que, construida sobre la imagen de la Piedad, cerraba un volumen sobre la Pasión de Cristo, mientras que aquí se incorporaba un poema sobre la vida de María para rematar un impreso que comenzaba con la narración de ésta en sus capítulos iniciales y en el cual, conteniendo los primeros años de Jesús, el co-protagonismo de la Virgen resultaba notable. Sabemos, por lo tanto, que hubo intervencionismo en la preparación de este poema para la imprenta, pero es fundamental tener en cuenta que se dispuso de muy poco tiempo para ello. Eso es así porque la Vida se incluyó al final de este impreso probablemente como una idea de última hora, al menos cuando se había producido ya la cuenta del original o, incluso, cuando ya se encontraba en cajas el cuaderno final o se había hecho una pre-impresión de él, porque, a diferencia de la Oració pero siguiendo su modelo de transmisión, aparece después del colofón y del índice del volumen, como evidencia de que se había incorporado tardía y espontáneamente ante la sobra de espacio en el último cuaderno impreso.

Muchas de las variaciones textuales de la versión impresa de la Vida son claramente atribuibles a un proceso de corrección de imprenta realizado por un técnico especializado en ello. Más allá del análisis interno completo que ofreceré en otro trabajo, valgan ahora como ejemplo dos variantes que considero clave para avalar esta hipótesis: por un lado, la sustitución del término 'senyora' por 'reyna' (v. 36) da lugar a lecciones equipolentes en apariencia, a pesar de que, en realidad, la lección sustitutoria genera un verso hipométrico; por otro lado, la actualización lingüística del término 'vogi' como 'roda' responde, sin duda, a una intervención del corrector de imprenta, porque la substitución de términos arcaicos o específicos por referentes lingüísticos más modernos y menos oscuros es uno de los rasgos caracterizadores de la adecuación lingüística de los textos impresos. Una palabra como 
'vogi' — habitual en otros textos de la época, como las poesías de Ausiàs March $(24,16)$, el Spill de Jaume Roig (v. 5380) o la Vita Christi de sor Isabel de Villena (cap. 48)— ${ }^{19}$ debió de resultar suficientemente compleja para que el corrector de este impreso optara por sustituirla por un término de mayor alcance lingüístico. Precisamente en La vida de la sacratíssima verge Maria de Miquel Peres, un texto en prosa que tiene en cuenta el poema corellano —necesariamente en su versión manuscrita—, ${ }^{20}$ aparece también este término en el primero de sus capítulos. ${ }^{21}$ Sin embargo, aunque así se mantuvo en su editio princeps (Valencia, Nicolás Spindeler, 1494), rápidamente fue sustituido por otro, no sabemos si ya en su segunda edición, hoy perdida (Barcelona, 1495) o, más bien, en la tercera de éstas, que también salía de unas prensas valencianas el 1506 (Juan Jofré o Pedro Posa). ${ }^{22}$ En un proceso habitual de corrección, el encargado de ésta manipula lecciones correctas o con sencillos errores de copista, de manera que llega a generar lecciones equivocadas muy difíciles de encontrar si no disponemos de la variante original en la tradición textual conservada (McKerrow 1998: 273-274). Así, el corrector de la edición de 1506 de La vida de la sacratíssima verge Maria de Miquel Peres, a diferencia de quien se encargó del impreso corellano de 1496, no entendió el término 'vogi', que consideró un error de cajista y, por esa razón, lo substituyó por 'goig', una palabra gráficamente parecida, pero de significado muy diferente. Este ejemplo ilustra la dificultad del término en aquel entonces, que el corrector de la edición corellana de 1496 fue capaz de sustituir por un sinónimo.

En consecuencia, dudo mucho de que tanto la variante 'reyna', como la vanalización léxica de 'vogi' sean intervenciones atribuibles a Joan Roís de Corella, porque la primera supone un error métrico que éste no habría dejado pasar y porque la segunda traiciona la excelencia de su modelo lingüístico. Si esto es así, habría que cuestionar la autoría de buena parte del resto de variaciones producidas en la versión impresa de la Vida, que no podríamos atribuir con tal ligereza a Corella: de hecho, muy probablemente, la mayoría de ellas serían responsabilidad del corrector, cuyas modificaciones ‘ja no solien ser revisades per l'autor, si era encara viu, i ni tan sols pel curador del text' (Ferrando 1999: 111).

\footnotetext{
${ }^{19}$ Para este catálogo de exemplos, parto de los aducidos en el DCVB. Sin embargo, ni en las ediciones de March — más tardías—, ni en las de Villena se produjo tal intervencionismo.

20 Porque l'editio princeps de esta obra es de 1494, mientras que la Vida de Corella se edita por primera vez en 1496, introduciendo importantes variaciones de imprenta, como se explica en este trabajo.

${ }^{21}$ Hacia el inicio de la narración, como en el poema de Joan Roís de Corella, lo que podría ser una huella de la relación entre ambas obras.

22 Remito a la reciente tesis de Carme Arronis (2012) para la edición crítica provisional de este texto, aunque no contiene todavía las variantes de la edición de 1506, que sí incluirá en la publicación resultante. Es por esto que es la autora quien, directamente, me ha confirmado esta información, lo que le agradezco desde aquí.
} 
En definitiva, no podemos negar la voluntad del editor y, probablemente, del autor para que éste apareciera como corrector del texto del Cartoixà impreso por Lope de la Roca, pero este reclamo comercial tampoco puede interpretarse de manera absoluta, imaginando a Corella como corrector editorial al uso. Sin duda, debió de ofrecer un texto bien revisado desde una perspectiva literaria y teológica, pero aquí debió de acabar buena parte de su función — si no toda-, porque a esto parece que se refieren las indicaciones del impreso: a una versión de autor revisada y considerada definitiva por éste en el momento de entregarla a imprenta. ${ }^{23}$ Asimismo, al proporcionar el original de la Vida debió de releer el poema y proporcionar una versión también avalada por él, pero no podemos saber si introdujo alguna modificación respecto de su versión previa, ni, en caso de haber sido así, tampoco es posible determinar de qué tipo y en qué grado de intervención. Además, no podemos olvidar que el impreso se refería específicamente a su papel como corrector del Cartoixà y, lógicamente, nada decía de este poema de remate incorporado en una fase avanzada de la edición. Si a esto unimos que hay claras evidencias de que la mayor parte de las intervenciones se produjeron en el taller de imprenta y de mano de un corrector especializado, con actuaciones y con errores más o menos evidentes, es muy complicado avalar el texto impreso como testimonio definitivo. Otra cosa bien diferente es que lo fuera el original que Corella entregó para ser impreso, aunque éste también habría estado mediatizado por un proceso editorial y no respondería, exclusivamente, a criterios de creación literaria.

\section{BIBLIOGRAFIA CITADA}

Almiñana Vallés, Josep, ed., 1984-1985. Obres de Joan Roiç de Corella, 2 vol. (València: Del Cénia al Segura).

Arronis Llopis, Carme, 2012. 'La vida de la sacratíssima verge Maria' de Miquel Peres: estudi i edició (Alicante: Universitat d'Alacant) [tesis doctoral].

Ferrando Francés, Antoni, 1999. 'El paper dels primers editors (1473-1523) en la fixació del català modern', Caplletra, 27: 109-36.

\footnotetext{
${ }^{23}$ De manera paralela a la manera de actuar de otras obras traducidas y a diferencia de la práctica habitual, que no siempre contaban con un original de autor: 'Les emmendationes a què fan referència els colofons podien referir-se tant al treball de revisió i de col·locació que suposava presentar adequadament l'original per als impressors com a les correccions que s'anaven introduint en les proves d'impremta a mesura que s'imprimia cada plec. La presentació de la Hystòria de Alexandre (Barcelona, 1481) com una versió feta per Lluís de Fenollet "en la present lengua valenciana", que ha estat "ara ab lo dit latí, toscà e encara castellà e altres lengües diligentment corregida", sembla referir-se al primer tipus de treball. Potser aquest sentit escau a les emmendationes de què parlen les obres de caire humanístic. En general, però, es devien referir al segon tipus de treball, com es dedueix de les fórmules que de tant en tant apareixen als contractes d'edició' (Ferrando 1999: 112-113).
} 
García Craviotto, Francisco, coord., 1989-1990. Catálogo general de incunables en bibliotecas españolas, 2 vols. (Madrid: Ministerio de Cultura-Dirección General del Libro y Bibliotecas).

Haebler, Conrado, 1903-1917. Bibliografía ibérica del siglo XV, 2 vols. (Leipzig-La Haya: Karl W. Hiersemann-Martinus Nijhoff).

Martos, Josep Lluís, 1999. 'El Cançoner de Maians (BUV MS 728): un cançoner d'autor de Joan Roís de Corella', in Miscel-lània Arthur Terry, Estudis de Llengua i Literatura Catalanes, 39 (Barcelona: Publicacions de l'Abadia de Montserrat), 3, pp. 93-113.

Martos, Josep Lluís, 2001. 'La génesis de un cancionero catalán de autor: Joan Roís de Corella y el Cançoner de Maians', in Canzonieri iberici, ed. Patrizia Botta, Carmen Parrilla \& Ignacio Pérez Pascual (A Coruña: Editorial Toxosoutos-Università di Padova, Universidade da Coruña), pp. 313-28.

Martos, Josep Lluís, 2005. 'El Còdex de Cambridge, el Cançoner de Maians y el Jardinet d'orats a través de la obra de Roís de Corella', in Los cancioneros españoles: materiales y métodos, ed. Manuel Moreno \& Dorothy S. Severin, Papers of the Medieval Hispanic Research Seminar', 43 (Londres: Queen Mary-University of London), pp. 113-40.

Martos, Josep Lluís, 2008. 'Fechas para la datación del Còdex de Cambridge', Critica del Testo, 11/3: 87-108.

Martos, Josep Lluís, en prensa. 'La poesia de Joan Roís de Corella: textos de rematada', in Joan Roís de Corella i el seu temps, (Valencia: Institució Alfons el Magnànim).

McKerrow, Ronald B., 1998. Introducción a la bibliografia material (Madrid: Arco Libros).

Miquel i Planas, Ramon, ed., 1913. Obres de J. Roiç de Corella (Barcelona: Casa Miquel-Rius).

Ribelles Comín, José, 1915. Bibliografía de la lengua valenciana, 1 (Madrid: Tipografía de la Revista de Archivos, Bibliotecas y Museos).

Riquer, Martí de, 1964. Història de la literatura catalana, 4 vols. (Barcelona: Ariel).

Romero Lucas, Diego, 2003. 'La traducción valenciana de las Mediationes Vitae Christi del cartujano Ludolfo de Sajonia. Las primeras ediciones valencianas impresas', Quaderns de Filologia. Estudis Literaris, 8: 299-314.

Romero Lucas, Diego, 2005. Catálogo gráfico descriptivo de la imprenta en Valencia (1473-1530) (Valencia: Universitat de València) [tesis doctoral].

Serrano y Morales, José Enrique, 1898-1899. Reseña histórica en forma de diccionario de las imprentas que han existido en Valencia desde la introducción del arte tipográfico en España hasta el año 1868 con noticias bio-bibliográficas de los principales impresores (Valencia: Imprenta de F. Doménech).

Soler, Abel, 2014. Joan Roís de Corella (1435-1497). Sintesi biogräfica $i$ aportació documental (Valencia: Acadèmia Valenciana de la Llengua).

Soriano Robles, Lourdes, Gemma Avenoza \& Montserrat Lamarca, 2007. 'Ludolfo de Sajonia, Terç del Cartoixà (Valencia, ca. 1495). Un nuevo ejemplar de la edición incunable', Gutenberg Jahrbuch, 82: 77-96.

\section{RESUMEN}

La vida de la sacratíssima verge Maria es un poema mariano de Joan Roís de Corella, que se conserva en una versión manuscrita y en otra impresa, con importantes variantes: el Cançoner de Mayans y las ediciones del Primer del Cartoixà (1496 y 1518). Se ha considerado éste último como la versión definitiva y, por esta razón, el poema se ha editado a partir de este testimonio. Sin embargo, hay razones que justifican que la versión impresa de este poema ha sido manipulada y no contiene la edición definitiva del poeta. El objetivo de este trabajo se centra en los datos externos, que contextualicen en su justa medida el proceso editorial, para poder emprender el análisis interno. 
PALABRAs CLAVE

Joan Roís de Corella, poesía religiosa, imprenta, mariología, variantes, edición crítica, transmisión textual.

\section{ABSTRACT}

La vida de la sacratíssima verge Maria is a Marian poem by Joan Roís de Corella, which is preserved in a manuscript version and in other printed with important variants: the Canconer de Mayans and editions of the Primer del Cartoixà (1496 and 1518). The latter has been considered as the definitive version and, for this reason, the poem has been published from this testimony. However, there are reasons justifying the printed version of this poem has been manipulated and does not contain the final edition of the poet. The objective of this work focuses on the external data, which properly contextualize the publishing process, to take the internal analysis.

\section{KEYWORDS}

Joan Roís de Corella, religious poetry, printing, Mariology, variants, critical edition, textual transmission. 